\title{
Prevalence of asthma-like symptoms by ISAAC video questionnaire in Mozambican schoolchildren
}

\author{
S. Mavale-Manuel1,2,3,4, O. Joaquim4, E. Nunes'1,4, A. Pedro1, \\ S. Bandeira1, E. Eduardo1, C. Macome1, L. Almeida1, A. Cossa1, \\ J. Malichocho1, L. Maciel1, E. Constance4, S. Marques4, A. Tembe4, \\ J. de Blic5, I. Annesi-Maesano2,3
}

ABSTRACT: Prevalence of asthma-like symptoms by ISAAC video questionnaire in Mozambican schoolchildren. S. Mavale-Manuel, O. Joaquim, E. Nunes, A. Pedro, S. Bandeira, E. Eduardo, C. Macome, L. Almeida, A. Cossa, J. Malichocho, L. Maciel, E. Constance, S. Marques, A. Tembe, J. de Blic, I. Annesi-Maesano.

Background. The International Study of Asthma and Allergies in Childhood (ISAAC) video questionnaire was developed to overcome the language and cultural differences in the assessment of asthma-like symptoms.

Methods. 27 schools were included in the Maputo Asthma and Allergies in childhood Study (MAPAAS) using ISAAC methods, and a video questionnaire (VQ) was administered to 1614 adolescents 13-14 years old of 20 schools located in urban, suburban and semi-rural areas of Maputo (Mozambique). Simultaneously, they also replied to the ISAAC written questionnaire (WQ).

Results. According to the video questionnaire, the prevalence of current asthma was $11.9 \%$ (compared with
$13.3 \%$ using the written questionnaire). Wheezing after exercise in the last year was reported by about $21 \%$. Females reported more frequent wheezing after exercise than males $(p<.001)$. The prevalence of nocturnal cough in the last year was $\mathbf{2 4 . 7 \%}$, and was more frequent in the suburban area (p<.001). "Severe attacks of asthma" was reported by $11.9 \%$ of the individuals. Teenagers instructed in the suburban schools reported more severe asthma-like symptoms than others $(p<.05)$. There was a poor correlation between the WQ and the AVQ3.0 (kappa coefficients varied from 0.09 to 0.24). The lowest agreement was observed for the question regarding severe attacks of asthma. Agreement was better in terms of specificity than in terms of sensitivity.

Conclusions. In spite of the poor agreement between the written and the video questionnaires, the prevalence of asthma symptoms estimated using the video questionnaire confirms that asthma is an important public health problem in Maputo.

Monaldi Arch Chest Dis 2006; 65: 4, 189-195.

Keywords: Allergy, asthma, children, ISAAC, mozambique, video questionnaires.

1 Maputo Central Hospital - Department of Paediatrics, Mozambique.

2 INSERM, U707: EPAR, Paris, F-75012 France.

3 Université Pierre et Marie Curie - Paris 6, UMR-S 707: EPAR Paris, F-75012 France.

4 University Eduardo Mondlane, Faculty of Medicine, Maputo, Mozambique.

5 Hôpital Necker Enfants-Malades Paris, France.

Correspondence: Isabella Annesi-Maesano; EPAR UMR-S 707 INSERM, Paris, France; EPAR UMR-S 707 UPMC, Paris 6, Paris, France; Medical School St-Antoine, 27 rue Chaligny 75571 Paris CEDEX 12, France; e-mail: annesi@u707.jussieu.fr

\section{Introduction}

Recent studies have reported a high prevalence of asthma symptoms in the world, particularly among children [1]. Asthma prevalence is variable among the countries and it is suggested that the variation may be due to differences in the diagnostic criteria and study methods used. In epidemiological studies, asthma has commonly been defined in the following ways:
1) the self-reporting of asthma (with or without the physician's confirmation) or asthma-like symptoms (wheeze, whistling, nocturnal cough and exercise induced dyspnoea) [2]; and

2) the existence of bronchial hyperresponsiveness as assessed by a challenge to special stimuli (histamine, methacholine, cold air, exercise...).

Indeed, there are potential problems associated both with asthma-like symptoms arising from sub- 
jective symptoms recognition and recall and with the under diagnosis of asthma depending either on the health care system or on age, sex and smoking habits of the individuals. Furthermore, the affordability of clinical tests like bronchial challenges depends on the health systems or on resources. The International Study of Asthma and Allergies in Childhood (ISAAC) was intended to provide an accurate assessment of asthma prevalence in children from differing language and cultures [4]. The ISAAC protocol for measuring asthma prevalence and severity in 13-14 years old schoolchildren comprises a self-completed written questionnaire (WQ) based on self-reported asthma-like symptoms and a video questionnaire. In the ISAAC phase I, English speaking countries have reported a higher prevalence of asthma symptoms [5], which was attributed also to a better understanding of the word "wheezing" in English speaking individuals, as wheezing does not exist in all languages. The use of video constitutes an attempt to overcome the translation problems associated with the written questionnaire as population with different cultural and language background may vary widely in the interpretation of the same questions [6]. Furthermore, it was suggested that each country needs to check the validity of both types of questionnaire provided by ISAAC with its own local data [7]. The aim of this study was to evaluate the concordance between the written and video questionnaire in Mozambican school children.

\section{Methods}

\section{STUDY POPULATION}

In the frame of the Maputo Asthma and Allergies in childhood Study (MAPAAS), 21 primary schools and 6 secondary schools were randomly selected from a total of 126 schools registered in Maputo by stratifying for geographic (urban, suburban and semi-rural) location and inhabitant's density so that to be representative of the distribution of the population of children and adolescents in Maputo. Regarding this stratification, 10 were in the urban area, 12 in the suburban area and 5 in the semi-rural area. All schools but one were public. We selected children by their actual age, regardless of the grade within the school by selecting several grades. The inclusion of the right class of age was made by visiting each classroom in each school and requesting those who attained 13 years of age and at most 14 years 11 months to stand up. Those remaining seated were requested to vacate the class. The others were enrolled in this survey. Teenagers were invited to complete a written questionnaire and in a sub-sample to reply to a video questionnaire.

\section{QUESTIONNAIRES}

\section{Written questionnaire}

The ISAAC written questionnaires (WQ) was presented to students in the Portuguese version.

The WQ includes questions on wheezing and cough symptoms, previous diagnostics of asthma, and questions on rhinitis and eczema. The written questionnaire on asthma comprises 5 questions that correspond to the 5 sequences depicted in the video questionnaire. The questions on asthma-like symptoms are:

1) Have you had wheezing or whistling in the chest in the last 12 months?

2) In the last 12 months, you chest sounded wheezy during or after exercise?

3) In the last 12 months, how often, on average has your sleep been disturbed due to wheezing? (Never woken with wheezing/ less than one night per week / one or more nights per week).

4) In the last 12 months, have you had a dry cough at night, apart from a cold or chest infection?

5) In the last 12 months, has wheezing ever been severe enough to limit you speech to only one or too words at time between breaths?

\section{Video questionnaire}

The International Version of the ISAAC video questionnaire (AVQ 3.0) was used. The international version was developed to make the exercise sequence more universally applicable, by showing running rather than indoor aerobic exercise, and also to provide ethnic diversity amongst the subjects in the video. The video contains five short sequences of asthma symptoms and signs. The first sequence shows a young person seated with clearly audible wheezing, but without breathlessness and no evidence of airway obstruction. Four further sequences shown in the video are:

1) exercise-induced wheezing;

2) walking at night with wheezing;

3) nocturnal coughing; and

4) a final sequence showing a severe attack of asthma.

Each sequence is followed by three questions asking the respondent if their breathing has ever been like the person's in the video, if "yes" in the last 12 months?" and if "yes" again in the last month?". The field researcher read the questions, and teenagers were asked to mark down whether they themselves had experienced such symptoms using a one-page printed answers sheet. The video questionnaire took about 7 minutes to be administered, and the term "asthma" was not mentioned during this time.

\section{STUDY DESIGN}

After completing the written questionnaire, the children themselves were shown the video and answered questions at the time. In accordance with the ISAAC methodology, after the completion of the WQ, this was collected by members of the staff and, when the logistic conditions allowed it, adolescents were invited to answer the AVQ3.0.

\section{STATISTICAL ANALYSIS}

The Kappa index [8] was used to find the degree of agreement between the ISAAC AVQ3.0 and WQ on asthma symptoms in the last 12 months. Simultaneously the agreement was com- 
puted as the ratio of the number of concordant responses to the total of the population. The data was entered using Microsoft Office Access 2000 and analyzed with STATA Intercooled version 8.2 (StataCorp 4905 Lakeway Drive College Station, Texas 77845 USA).

\section{ETHICAL CONSIDERATIONS}

Permission to conduct the study was obtained from the Bio-ethics committee in Mozambique, the Department of Schools Education, school Principals, the parents of the children and all participants gave a verbal consent to participate.

\section{Results}

\section{Socio-demographic characteristics}

\section{SCHOOLS}

27 schools participated in ISAAC WQ and 20 schools in both WQ and AVQ 3.0 (77.7\%). Con- trarily as expected, urban schools had fair participation in video questionnaire (75\%). The highest school participation rate in AVQ3.0 was observed in the suburban area (90\%). Semi-rural areas present the lowest participation in AVQ3.0 (table 1).

\section{AdOLESCENTS}

2630 children completed the WQ. The video and written questionnaire was administrated to 1614 children $(61 \%)$. Of a total of 1614 adolescents, $743(46 \%)$ were male and $871(54 \%)$ female.

\section{Prevalence of asthma-like symptoms}

The global prevalence of current asthma according to AVQ3.0 was $11.9 \%$ compared to $13.3 \%$ in the case of current wheeze (wheezing in the last 12 months) according to WQ. In the schools of urban, suburban and semi rural area, the prevalence of video current wheeze is similar (table 2). Students of suburban area reported more frequently

Table 1. - Distribution and location of schools

\begin{tabular}{lccc}
\hline Location of schools & $\begin{array}{c}\text { Written questionnaire } \\
\text { (number of schools) }\end{array}$ & $\begin{array}{c}\text { Video questionnaire } \\
\text { (number of schools) }\end{array}$ & $\begin{array}{c}\text { Rate of video participation } \\
(\%)\end{array}$ \\
\hline Urban & 12 & 9 & 75 \\
Suburban & 10 & 9 & 90 \\
Semi-rural & 5 & 2 & 40 \\
Total & 27 & 20 & 74 \\
\hline
\end{tabular}

Table 2. - Prevalence of video questionnaire asthma-like symptoms by location of schools

\begin{tabular}{|c|c|c|c|c|c|c|c|c|c|}
\hline & \multicolumn{2}{|c|}{ Urban } & \multicolumn{2}{|c|}{ Suburban } & \multicolumn{2}{|c|}{ Rural } & \multicolumn{2}{|c|}{ Total } & \multirow[b]{2}{*}{$\mathbf{P}$} \\
\hline & Freq & $\%$ & Freq & $\%$ & Freq & $\%$ & Freq & $\%$ & \\
\hline Population & 419 & 25.9 & 1046 & 64.8 & 149 & 9.2 & 1614 & 100 & \\
\hline \multicolumn{10}{|l|}{ Asthma-life symptoms } \\
\hline $\begin{array}{l}\text { Wheezing (while at rest) } \\
\text { Ever } \\
\text { In last year } \\
\text { One or more per month }\end{array}$ & $\begin{array}{l}85 \\
47 \\
35\end{array}$ & $\begin{array}{r}20.3 \\
11.2 \\
8.4\end{array}$ & $\begin{array}{l}234 \\
129 \\
133\end{array}$ & $\begin{array}{l}22.4 \\
12.3 \\
12.7\end{array}$ & $\begin{array}{r}29 \\
17 \\
9\end{array}$ & $\begin{array}{r}19.5 \\
11.4 \\
6.0\end{array}$ & $\begin{array}{l}348 \\
193 \\
177\end{array}$ & $\begin{array}{l}21.6 \\
11.9 \\
10.9\end{array}$ & $\begin{array}{r}\text { NS } \\
\text { NS } \\
<.05\end{array}$ \\
\hline $\begin{array}{l}\text { Wheezing after exercise } \\
\text { Ever } \\
\text { In last year } \\
\text { One or more per month }\end{array}$ & $\begin{array}{r}162 \\
103 \\
86\end{array}$ & $\begin{array}{l}38.7 \\
24.6 \\
20.5\end{array}$ & $\begin{array}{l}365 \\
207 \\
243\end{array}$ & $\begin{array}{l}34.9 \\
19.8 \\
23.2\end{array}$ & $\begin{array}{l}46 \\
27 \\
25\end{array}$ & $\begin{array}{l}30.9 \\
18.1 \\
16.8\end{array}$ & $\begin{array}{l}573 \\
337 \\
354\end{array}$ & $\begin{array}{l}35.5 \\
20.9 \\
21.9\end{array}$ & $\begin{array}{l}\text { NS } \\
\text { NS } \\
\text { NS }\end{array}$ \\
\hline $\begin{array}{l}\text { Waking with wheeze } \\
\text { Ever } \\
\text { In last year } \\
\text { One or more per month }\end{array}$ & $\begin{array}{l}80 \\
40 \\
36\end{array}$ & $\begin{array}{r}19.1 \\
9.6 \\
8.6\end{array}$ & $\begin{array}{r}172 \\
102 \\
97\end{array}$ & $\begin{array}{r}16.4 \\
9.8 \\
9.3\end{array}$ & $\begin{array}{r}25 \\
18 \\
8\end{array}$ & $\begin{array}{r}16.8 \\
12.1 \\
5.4\end{array}$ & $\begin{array}{l}277 \\
160 \\
141\end{array}$ & $\begin{array}{r}17.1 \\
9.9 \\
8.7\end{array}$ & $\begin{array}{l}\mathrm{NS} \\
\mathrm{NS} \\
<.001\end{array}$ \\
\hline $\begin{array}{l}\text { Waking with cough } \\
\text { Ever } \\
\text { In last year } \\
\text { One or more per month }\end{array}$ & $\begin{array}{r}170 \\
95 \\
74\end{array}$ & $\begin{array}{l}40.6 \\
22.7 \\
17.7\end{array}$ & $\begin{array}{l}492 \\
283 \\
274\end{array}$ & $\begin{array}{l}47.0 \\
27.1 \\
26.2\end{array}$ & $\begin{array}{l}43 \\
21 \\
17\end{array}$ & $\begin{array}{l}28.9 \\
14.1 \\
11.4\end{array}$ & $\begin{array}{l}705 \\
399 \\
365\end{array}$ & $\begin{array}{l}43.7 \\
24.7 \\
22.6\end{array}$ & $\begin{array}{l}<.001 \\
<.01 \\
<.001\end{array}$ \\
\hline $\begin{array}{l}\text { Severe attack of asthma } \\
\text { Ever } \\
\text { In last year } \\
\text { One or more per month }\end{array}$ & $\begin{array}{l}74 \\
38 \\
25\end{array}$ & $\begin{array}{r}17.7 \\
9.1 \\
5.6\end{array}$ & $\begin{array}{l}239 \\
133 \\
140\end{array}$ & $\begin{array}{l}22.9 \\
12.3 \\
13.4\end{array}$ & $\begin{array}{l}30 \\
22 \\
18\end{array}$ & $\begin{array}{l}20.1 \\
14.8 \\
12.1\end{array}$ & $\begin{array}{l}343 \\
193 \\
183\end{array}$ & $\begin{array}{l}21.3 \\
11.9 \\
11.3\end{array}$ & $\begin{array}{c}\mathrm{NS} \\
\mathrm{NS} \\
<.001\end{array}$ \\
\hline
\end{tabular}


waking with cough ever and in the last year (table 2). The prevalence of wheezing after exercise in the last year was about $21 \%$, and there was no location difference (table 2). The prevalence of nocturnal cough in the last year was $24.7 \%$. The prevalence of current waking with wheeze was $9.9 \%$, without any significant location difference (table 2).

Female schoolchildren reported significantly more frequent wheezing after exercise $(p<.001)$ (table 3). No other differences were observed among sexes.

\section{Severity of asthma}

Severe attacks of asthma were reported by $11.9 \%$ of the individuals (table 2). Teenagers instructed in the suburban schools reported severe asthma-like symptoms significantly more severe regardless wheezing while at rest, waking with wheeze, waking with cough and clearly severe attack of asthma one or more time per month (table 2 ). Female adolescents reported significantly more severe attacks of asthma than male (table 3 ).

\section{Agreement between $W Q$ and $A V Q 3.0$}

Agreement between responses to the 5 corresponding questions "wheezing at rest, nocturnal wheezing, exercise wheezing, night cough and severe wheezing" in the AVQ3.0 and WQ respectively were moderate and weak, although statistically significant at the level of 0.05 , with Kappa indices varying from 0.09 to 0.24 . Severe wheezing yielded the weakest correlation (table 4).

Table 3. - Prevalence of asthma-like symptoms by gender

\begin{tabular}{|c|c|c|c|c|c|c|c|}
\hline & \multicolumn{2}{|c|}{ Male } & \multicolumn{2}{|c|}{ Female } & & \multicolumn{2}{|c|}{ All } \\
\hline & Freq & $\%$ & Freq & $\%$ & & Freq & $\%$ \\
\hline Population & 743 & 46 & 871 & 54 & $\mathrm{p}$ & 1614 & 100 \\
\hline \multicolumn{8}{|l|}{ Asthma symptoms } \\
\hline \multicolumn{8}{|l|}{ Wheezing (while at rest) } \\
\hline Ever & 154 & 20.7 & 194 & 22.3 & NS & 348 & 21.6 \\
\hline In last year & 81 & 10.9 & 112 & 12.9 & NS & 193 & 11.9 \\
\hline One or more per month & 71 & 9.6 & 106 & 12.2 & NS & 177 & 11.0 \\
\hline \multicolumn{8}{|l|}{ Wheezing after exercise } \\
\hline Ever & 236 & 31.8 & 337 & 38.7 & $<.05$ & 573 & 35.5 \\
\hline In last year & 131 & 17.6 & 206 & 23.7 & $<.05$ & 337 & 20.9 \\
\hline One or more per month & 147 & 19.8 & 207 & 23.8 & .05 & 354 & 21.9 \\
\hline \multicolumn{8}{|l|}{ Waking with wheeze } \\
\hline Ever & 140 & 18.8 & 137 & 15.7 & NS & 277 & 17.2 \\
\hline In last year & 81 & 10.9 & 79 & 9.1 & NS & 160 & 9.9 \\
\hline One or more per month & 66 & 8.9 & 77 & 8.8 & NS & 143 & 8.9 \\
\hline \multicolumn{8}{|l|}{ Waking with cough } \\
\hline Ever & 317 & 42.7 & 388 & 44.6 & NS & 705 & 43.7 \\
\hline In last year & 173 & 23.3 & 226 & 26.0 & NS & 399 & 24.7 \\
\hline One or more per month & 160 & 21.5 & 205 & 23.6 & NS & 365 & 22.6 \\
\hline \multicolumn{8}{|l|}{ Severe attack of asthma } \\
\hline Ever & 141 & 19.0 & 202 & 23.2 & $<.05$ & 343 & 21.3 \\
\hline In last year & 77 & 10.3 & 116 & 13.3 & .0680 & 193 & 12.0 \\
\hline One or more per month & 71 & 9.6 & 112 & 12.9 & $<.05$ & 183 & 11.3 \\
\hline
\end{tabular}

Table 4. - Agreement between written and video questionnaires

\begin{tabular}{|c|c|c|c|c|c|c|c|c|c|c|c|}
\hline \multirow{3}{*}{$\begin{array}{l}\text { written Questionnaire } \\
\text { video Questionnaire }\end{array}$} & \multirow{2}{*}{\multicolumn{2}{|c|}{$\begin{array}{l}\text { Yes } \\
\text { Yes }\end{array}$}} & \multirow{2}{*}{\multicolumn{2}{|c|}{$\begin{array}{l}\text { Yes } \\
\text { No }\end{array}$}} & \multirow{3}{*}{$\begin{array}{c}\text { No } \\
\text { Yes } \\
n\end{array}$} & \multirow{2}{*}{\multicolumn{3}{|c|}{$\begin{array}{l}\text { No } \\
\text { No }\end{array}$}} & \multirow[t]{3}{*}{ Agreement (\%) } & \multirow{3}{*}{ Kappa } & \multirow{3}{*}{ P-value } \\
\hline & & & & & & & & & & & \\
\hline & $\mathrm{n}$ & $\%$ & $\mathrm{n}$ & $\%$ & & $\%$ & $\mathrm{n}$ & $\%$ & & & \\
\hline 1. Wheeze at rest & 65 & (4) & 134 & $(8.3)$ & 128 & $(7.9)$ & 1287 & (79.7) & 83.7 & 0.24 & $<.001$ \\
\hline 2. Exercise wheeze & 75 & $(4.6)$ & 73 & $(4.5)$ & 262 & $(16.2)$ & 1204 & (74.6) & 79.4 & 0.21 & $<.0001$ \\
\hline 3. Night wheeze & 50 & (3.1) & 106 & $(6.5)$ & 110 & $(6.8)$ & 1348 & $(83.5)$ & 86.6 & 0.24 & $<.001$ \\
\hline 4. Night cough & 108 & (6.7) & 145 & (8.9) & 291 & (18) & 1070 & $(66.2)$ & 72.9 & 0.17 & $<.0001$ \\
\hline 5. Severe wheeze & 19 & (1.1) & 50 & (3.1) & 174 & (10.7) & 1371 & $(84.9)$ & 86.0 & 0.09 & $<.0001$ \\
\hline
\end{tabular}

$\mathrm{P}<0.005$ indicating significant agreement. 
Agreement was better in terms of specificity than in terms of sensitivity. The lowest Kappa values were found in the rural zone (table 5).

\section{Discussion}

The prevalence of current asthma is $13.3 \%$ using ISAAC written and $11.9 \%$ using ISAAC video questionnaire. To our knowledge, this is the first study which compares these two types of questionnaires in African Portuguese speaking countries.

Although Portuguese is the official language in Mozambique, there are several traditional languages. Maputo, the capital, is an urbanised town and there are miscellaneous of cultures, the predominant traditional language is Ronga and Xangana. For this survey, we used the Portuguese translation of ISAAC written questionnaire and the international version of video questionnaire AVQ3.0. We did not include tests for bronchial hyper-responsiveness due to their high costs.

Only $61 \%$ of eligible adolescents have answered the video questionnaire. One of the causes is due to limitation of material supply (television and video). Sometimes AVQ3.0 was administrated one or two days after WQ and in this case we lost some children. Conversely, video questionnaires were not easily administered in all schools due to local logistical conditions such as absence of electricity. During the WQ, we observed that the majority of children did not understand well the translated terms of wheezing in Portuguese "Pieira, assobios no peito ou chios". Thai's study shows that most asthmatic children as well as controls used terms to describe wheeze different from the ones chosen by medical personnel [9]. In addition, some studies suggest that to arrive at the correct preva-

Table 5. - Agreement between written and video questionnaires by zones

\begin{tabular}{|c|c|c|c|c|c|c|c|c|c|c|c|c|}
\hline & \multicolumn{8}{|c|}{ WQ/AVQ } & \multirow{3}{*}{$\%$ Agreement } & \multirow{3}{*}{ TOTAL } & \multirow{3}{*}{ Kappa } & \multirow{3}{*}{$\mathrm{p}$} \\
\hline & \multicolumn{2}{|c|}{ yes/yes } & \multicolumn{2}{|c|}{ yes/no } & \multicolumn{2}{|c|}{ no/yes } & \multicolumn{2}{|c|}{ no/no } & & & & \\
\hline & $\mathrm{N}$ & $\%$ & $\mathrm{~N}$ & $\%$ & $\mathrm{~N}$ & $\%$ & $\mathrm{~N}$ & $\%$ & & & & \\
\hline \multicolumn{13}{|c|}{ 1. Wheezing while at rest } \\
\hline Urban & 21 & 5.0 & 40 & 9.5 & 26 & 6.2 & 332 & 79.2 & 84.2 & 419 & 0.30 & $<0.0001$ \\
\hline SemiUrban & 42 & 4.0 & 79 & 7.6 & 87 & 8.3 & 838 & 80.1 & 84.1 & 1046 & 0.25 & $<0.0001$ \\
\hline Rural & 2 & 1.3 & 15 & 10.1 & 15 & 10.1 & 117 & 78.5 & 79.9 & 149 & 0.30 & 0.48 \\
\hline Total & 65 & 4.0 & 134 & 8.3 & 128 & 7.9 & 1287 & 79.7 & 83.8 & 1614 & 0.24 & $<0.001$ \\
\hline \multicolumn{13}{|c|}{ 2. Wheezing after exercise } \\
\hline Urban & 23 & 5.5 & 25 & 6.0 & 80 & 19.1 & 291 & 69.5 & 74.9 & 419 & 0.18 & $<0.0001$ \\
\hline SemiUrban & 47 & 4.5 & 40 & 3.8 & 160 & 15.3 & 799 & 76.4 & 80.9 & 1046 & 0.23 & $<0.0001$ \\
\hline Rural & 5 & 3.4 & 8 & 5.4 & 22 & 14.8 & 114 & 76.5 & 79.9 & 149 & 0.18 & 0.02 \\
\hline Total & 75 & 4.6 & 73 & 4.5 & 262 & 16.2 & 1204 & 74.6 & 79.2 & 1614 & 0.14 & $<0.001$ \\
\hline \multicolumn{13}{|c|}{ 3. Nocturnal Wheeze } \\
\hline Urban & 12 & 2.9 & 30 & 7.2 & 28 & 6.7 & 349 & 83.3 & 86.2 & 419 & 0.22 & $<0.0001$ \\
\hline SemiUrban & 37 & 3.5 & 63 & 6.0 & 65 & 6.2 & 881 & 84.2 & 87.8 & 1046 & 0.30 & $<0.0001$ \\
\hline Rural & 1 & 0.7 & 13 & 8.7 & 17 & 11.4 & 118 & 79.2 & 79.9 & 149 & 0.22 & 0.72 \\
\hline Total & 50 & 3.1 & 106 & 6.6 & 110 & 6.8 & 1348 & 83.5 & 86.6 & 1614 & 0.20 & $<0.001$ \\
\hline \multicolumn{13}{|c|}{ 4. Nocturnal cough } \\
\hline Urban & 24 & 5.7 & 40 & 9.5 & 71 & 16.9 & 284 & 67.8 & 73.5 & 419 & 0.15 & $<0.001$ \\
\hline SemiUrban & 81 & 7.7 & 81 & 7.7 & 202 & 19.3 & 682 & 65.2 & 72.9 & 1046 & 0.21 & 0.03 \\
\hline Rural & 3 & 2.0 & 24 & 16.1 & 18 & 12.1 & 104 & 69.8 & 71.8 & 149 & 0.15 & 0.69 \\
\hline Total & 108 & 6.7 & 145 & 9.0 & 291 & 18.0 & 1070 & 66.3 & 73.0 & 1614 & 0.12 & $<0.001$ \\
\hline \multicolumn{13}{|c|}{ 5. Severe wheeze } \\
\hline Urban & 6 & 1.4 & 15 & 3.6 & 32 & 7.6 & 366 & 87.4 & 88.8 & 419 & 0.15 & $<0.001$ \\
\hline SemiUrban & 12 & 1.1 & 28 & 2.7 & 121 & 11.6 & 885 & 84.6 & 85.8 & 1046 & 0.08 & $<0.001$ \\
\hline Rural & 1 & 0.7 & 7 & 4.7 & 21 & 14.1 & 120 & 80.5 & 81.2 & 149 & 0.15 & 0.57 \\
\hline Total & 19 & 1.2 & 50 & 3.1 & 174 & 10.8 & 1371 & 84.9 & 86.1 & 1614 & 0.08 & $<0.001$ \\
\hline
\end{tabular}

Table. 6. - The ISAAC written questions on asthma and their corresponding 5 sequences in the video questionnaire

\section{Written questionnaire}

1. Have you had wheezing or whistling in the chest in the last 12 months?

2. In the last 12 months, you chest sounded wheezy during or after exercise?

3. In the last 12 months, how often, on average has your sleep been disturbed due to wheezing? (Never woken with wheezing/ less than one night per week / one or more nights per week);

4. In the last 12 months, have you had a dry cough at night, apart from a cold or chest infection?

5. In the last 12 months, has wheezing ever been severe enough to limit you speech to only one or too words at time between breaths?

\section{Video questionnaire}

Moderate wheezing at rest

Wheezing after exercise

Waking at night with wheezing

Waking at night with cough

Severe attack of asthma with wheezing and breathlessness at rest 
lence of wheeze within each ethnic group, one would need to determine the actual word the patients use to denote "wheeze" in their local language [9]. We have previously demonstrated that knowledge concerning asthma and asthma-like symptoms is weak in Mozambique [10]. Indeed we had to mimic the sound of wheezing to reduce some language bias associated to written questionnaire. In theory, the video questionnaire has been designed to circumvent the problem. However, video questionnaire has often failed in its aim [11].

Our data suggests poor correlation between the two questionnaires on all questions, overall in the case of the question regarding severe wheeze. The validity of ISAAC questionnaire is likely to vary across cultures and languages. Moreover, the number of positive responses to the video was generally lower than for the similar questions with the written questionnaire. In the rural areas where children have clearly more socio-economic background (poverty, lower school performances), there was consistently disagreement between the two types of questionnaires. Like us, others studies had report lower prevalence in video than in the written questionnaire $[12,13]$. One of the possible reasons is that signs that are obvious enough to be visible or audible on a video are likely to represent more severe symptoms than the full spectrum from mild to severe asthma covered by the written questionnaire [13], and secondly may be due to problem to understanding the term [12].

The international version of AVQ3.0 has been validated in adolescents school children against methacholine airway hyperresponsiveness to hypertonic saline, and reported good agreement between written and video ISAAC questionnaires, and the AVQ3.0 was equivalent to the ISAAC WQ in its ability to predict airway hyperresponsiveness to hypertonic saline $[6,14]$.

The video question may have been interpreted as illustrating more severe wheezing than that experienced by individuals. We observed that some children were "assustados" surprised when some video sequences were presented. This is supported by the higher prevalence of wheezing from written question compared to the video in 90 of the 99 centres [11]. In the Ivory Coast the prevalence of asthma decreased to $3.34 \%$ when the video questionnaire was used [15]. In France, the degree of concordance between written and video questions measured by the kappa coefficient was low. One possible explanation is the fact that written and video questions do not represent exactly the same situation. Even if some studies have shown, with the measurement of bronchial hyperreactivity, that the video questionnaire is at least as effective as the written questionnaire to identify asthma symptoms, there is need for more adjusted between the two [16].

In the present study, the prevalence of asthma symptoms obtained using the video questionnaire decreased a little, however, confirms that asthma is a public health problem in Mozambique. The prevalence of exercise wheezing and night cough in the last year had decreased by about $20 \%$ using the video questionnaire. The prevalence of current asthma (wheezing in the last 12 months) is relatively lower in the video questionnaire and not significantly different between the 3 areas of Maputo. Conversely asthma severity (speech disturbance and severe attack of asthma) was more frequently reported by video questionnaire than written questionnaire especially in the rural areas. It is reported that children who responded negatively to the written questionnaire but positively to the video, presumably these children were uncertain about the meaning of the written term but recognised the symptom when it was shown to them audiovisually [11]. Regarding the sex, the results are comparable with that of the written questionnaire. Girls had significantly more exercise wheeze and asthma appears be more severe $(\mathrm{p}=0.05)$. The questionnaires show good negative agreement because children answered negatively to written questions they tended to answer negatively when they saw the video. One of the drawbacks of the video questionnaire is that it requires a classroom setting for its administration and electricity. In some African schools it was very complicated to complete.

In conclusion, in Maputo the prevalence of current asthma is comparable using written and video questionnaire (13.3 and $11.9 \%$ respectively). Agreement between the WQ and AVQ3.0 is weak and kappa varied from 0.09 to 0.24 . A valid method for detecting asthma in epidemiological studies in situation in which there are language difficulties is still required.

Acknowledgements: The authors are indebted to the children, families and schools that took part in the present survey; and to SCAC, Ambassade de France in Mozambique (M. José da Costa), who made the study possible by supporting through a grant $\mathrm{Dr} \mathrm{SMM}$ during her $\mathrm{PhD}$ thesis.

\section{References}

1. Burney PGJ, Chinn S, Rona RJ. Has the prevalence of asthma increased in children? Evidence from the national study of health and growth 1973-1986. BMJ 1990; 300: 1306-10.

2. Liard R, Neukirch F. Questionnaires: a major instrument for respiratory epidemiology. In: Respiratory Epidemiology in Europe (Annesi-Maesano I, Gulsvik A, Viegi G eds). Eur Respir Monograph 2000; 15: 154-66.

3. Chinn S, Sunyer J. Bronchial Hyperresponsiveness. In: Respiratory Epidemiology in Europe (Annesi-Maesano I, Gulsvik A, Viegi G eds). Eur Respir Monograph 2000; 15: 199-215.

4. Asher MI, Keil U, Anderson AR, et al. International Study of Asthma and Allergies in Childhood (ISAAC): rationale and methods. Eur Respir J 1995; 8: 483-91.

5. Stering committee. Worldwide variation in prevalence of symptoms of asthma, allergic rhinoconjunctivitis, and atopic eczema: ISAAC. Lancet 1998; 351: 1225-32.

6. Lai CK, Chan JK, Chan A, et al. Comparison of the ISAAC video questionnaire (AVQ 3.0) with the ISAAC written questionnaire for estimating asthma associated with bronchial hyperreactivity. Clin Exp Allergy 1997; 27: 540-5.

7. Hong SJ, Klim JM, Rah YH, et al. The validity of the ISAAC written questionnaire and the ISAAC video questionnaire (AVQ3.0) for predicting asthma associat- 
ed with bronchial hyperreactivity in a group of 13-14 year old Koren schoolchildren. J Korean Med Sci 2003; 18: 48-52.

8. Bouyer J, Hémon D, Cordier S, et al. Epidémiologie. Principes et methods quantitatives. Les Editions INSERM, Paris, 1993, 498 pages.

9. Phankingthongkum S, Daengsuwan T, Visitsunthorn. How Thai children and adolescents describe asthma symptoms? Pediatr Allergy Imumonol 2002; 13: $119-24$.

10. Mavale-Manuel S, Duarte N, Alexandre F, et al. Knowledge, attitudes, and behavior of parents of asthmatic children in Maputo. J Asthma 2004; 41: 533-38.

11. Crane J, Mallol J, Beasley R, et al. Agreement between written and video questions for comparing asthma symptoms in ISAAC. Eur Respir $J$ 2003; 21: 455-61.

12. Pekkanen J, Remes S, Husman T, et al. Prevalence of asthma symptoms in video and written questionnaires among children in four regions of Finland. Eur Respir $J$ 1997; 10: 1787-94.

13. ISAAC Steering Committee. Worldwide variations in the prevalence of asthma symptoms: the International Study of Asthma and Allergies in Childhood (ISAAC). Eur Respir J 1998; 12: 315-35.

14. Gibson P, Henry R, Shah S, et al. Validation of the ISAAC video questionnaire (AVQ3.0) in adolescents from a mixed ethnic background. Clin Exp Allergy 2000; 30: 1181-87.

15. Koffi N, Aka J, Kouassi B, et al. Prévalence des maladies allergiques de l'enfant: résultats de l'enquete ISAAC - Cote d'Ivoire phase I. Rev Fr Allergol Immunol Clin 2000; 40: 539-47.

16. Quoix E, Hedlin G, Kopferchmitt C, et al. Comparison du questionnaire video et du questionnaire ecrit dans la mesure de la prevalence des symptomes d'asthme dans le cadre de l'enquate ISAAC de phase I. Rev Mal Respir 1997; 14: 4S61.

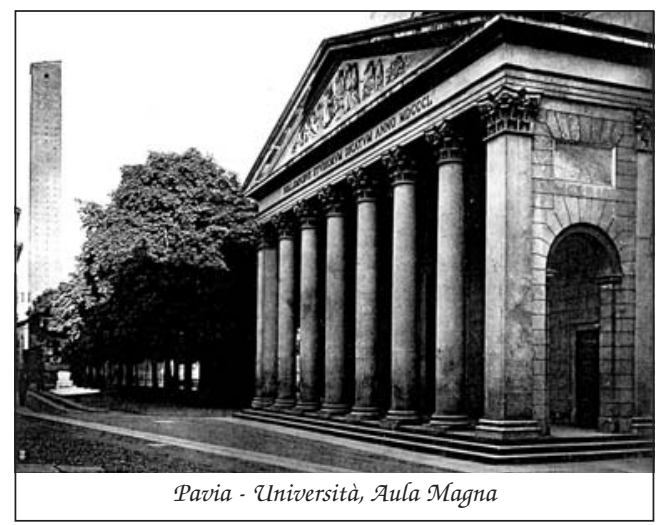

